\title{
LATE RESULTS IN TRANSTHORACIC HERNIOTOMIES
}

\author{
BY \\ TYGE CL. GERTZ, J. E. P. M. REGOUT, AND GREGERS THOMSEN \\ From the Department of Thoracic Surgery and Radiology, the University \\ Hospital, Copenhagen
}

The late results after surgical treatment of hiatus hernia are scarcely commented upon in the literature, and most re-examinations do not state if radiological examinations have been performed on all the patients during the period of follow-up. We find this to be indispensable. The purpose of this investigation has been to assess the late results in a group of patients suffering from hiatus hernia, all of whom were treated surgically and re-examined both clinically and radiologically.

Our indications for surgery in hiatus hernia do not differ from those usually stated in the literature. According to the latest contributions the congenital sliding hernia should be treated surgically as early as possible, before oesophagitis and shrinkage of the oesophagus make the reduction of the hernia difficult or impossible (Allison, 1948 ; Husfeldt, Thomsen, and Wamberg, 1951). The acquired sliding hernia does not need surgical treatment when it is small and only causes moderate symptoms. This group can be treated successfully with a bland diet, alkalis, antispasmodics, and postural measures, but herniotomy is indicated in those patients in whom the symptoms are progressing and who do not respond to medical treatment. Increasing size of the hernia, severe bleedings, and incarceration are also indications for operative treatment. The para-oesophageal hernia should, when causing pain, be operated upon because there is a danger of incarceration.

The surgical repair of hiatus hernia may either be performed by a thoracic or by an abdominal approach. Although Harrington (1948) advocates the latter method, most surgeons prefer the thoracic route (Sweet, 1948 ; Husfeldt and others, 1951 ; Soutter, 1947 ; Nuboer, 1949). The thoracic approach has the following advantages. The hernial sac, the oesophageal hiatus, and the cardia lie under direct vision and any adhesions may easily be freed. The oesophagus can when necessary be released right up to the aortic arch, and hence the cardia can be brought down below the diaphragm, even in cases where the cardia is found to lie well above the hiatus. In case of difficulties in reducing the hernia, a separate incision may be made in the diaphragm.

\section{MATERIAL}

Our material consists of 60 cases operated on during the years 1943-50. More than two-thirds, 43, have been operated upon during the last two years. This is not implying that we have become more active in our indications for surgery, but is partly explained because an increasing number of patients have been referred to us and partly because during that period we have taken a special interest in the congenital sliding hernia. 
The diagnosis has in every case been based on one or more radiological examinations, and the subdivision into para-oesophageal and sliding types is also based upon the results of these films. The radiological diagnosis of hiatus hernia is well known since the pioneering work of Åkerlund in 1926, and we do not intend to go further into this subject.

The distribution according to age and sex is shown in Table I, and also the ratio between the sliding type and the para-oesophageal type of hiatus hernia.

TABLE I

Distribution of Sixty Cases according to Age and SeX

\begin{tabular}{cc|c|c|c|c|c|c|c}
\hline \multicolumn{1}{c}{ Type } & Sex & $\begin{array}{c}0-10 \\
\text { Years }\end{array}$ & $\begin{array}{c}10-20 \\
\text { Years }\end{array}$ & $\begin{array}{c}20-30 \\
\text { Years }\end{array}$ & $\begin{array}{c}30-40 \\
\text { Years }\end{array}$ & $\begin{array}{c}\text { Above } \\
\text { 40 Years }\end{array}$ & Total \\
\hline Sliding hernia & $\cdots$ & $\mathrm{F}$ & 8 & 2 & 3 & 4 & 19 & 36 \\
& & $\mathrm{M}$ & 8 & 0 & 0 & 0 & 5 & 13 \\
\hline & Total & 16 & 2 & 3 & 4 & 24 & 49 \\
\hline $\begin{array}{c}\text { Para-oesophageal } \\
\text { hernia }\end{array}$ & $\mathrm{F}$ & 2 & 2 & 0 & 0 & 6 & 10 \\
\hline & $\mathrm{M}$ & 0 & 1 & 0 & 0 & 0 & 1 \\
\hline
\end{tabular}

In accordance with the literature the sliding type represents more than $80 \%$. Like other authors we have found the condition much more frequently in women than in men. An exception is the congenital type of the sliding hernia, where no sex difference is found. As for the age distribution, the frequency has two maxima, one in the ages below 10 years, especially representing the congenital type of sliding hernia, and the other in the ages above 40 years.

The relative frequency of sliding hernia in children in our material is due to the fact that we are including a type which may very easily be overlooked. In a previous paper (Husfeldt, Thomsen, and Wamberg, 1951) we have distinguished between two different types of congenital sliding hernias. The first represents the congenital short oesophagus; the second is characterized by a short oesophagus and a herniation of the cardia and upper part of the stomach, but without stricture of the lower part of the oesophagus, such as is found in the first type. This second type may be very difficult to diagnose and is easily overlooked on a routine radiological examination of the oesophagus and the stomach. In this paper we have not made a distinction between the two types, and we will only refer to it in the assessment of the operative results.

\section{SYMPTOMS}

Table II shows the incidence, in the various types of hiatus hernia, of the most common complaints, pain, dysphagia, and vomiting or regurgitation. Of these symptoms pain is the most variable. In some cases the pain consists of epigastric distress or vague substernal pain setting in during or shortly after meals, especially in the recumbent position. In other cases the pain is excruciating, radiating to the left side of the back or to the left shoulder and arm. This may come unconnected with meals, and often during sleep. 
TABLE II

INCIDENCE OF SyMPTOMS IN BOTH TYPeS OF HERNIA

\begin{tabular}{|c|c|c|c|c|c|}
\hline \multicolumn{2}{|l|}{ Type } & Total & Pain & Dysphagia & $\begin{array}{l}\text { Vomiting or } \\
\text { Regurgitation }\end{array}$ \\
\hline \multirow{2}{*}{ Sliding hernia } & Congenital & 19 & 2 & 5 & 19 \\
\hline & Acquired & 30 & 24 & 8 & 14 \\
\hline \multirow{2}{*}{ Para-oesophageal hernia } & Congenital & 5 & 2 & 0 & 2 \\
\hline & Acquired & 6 & 6 & 1 & 3 \\
\hline
\end{tabular}

In Table II we have also made a distinction between congenital and acquired forms of hiatus hernias based on the clinical data. For the sliding hernias this distinction is easy. In the congenital sliding hernia the symptoms start just after birth or at least in the first few months of neonatal life. The acquired form, on the other hand, is almost always found in the ages above 40 years, and symptoms only exceptionally occur before the age of 30 . The same classification of the paraoesophageal hernias is not quite as easy. These hernias may be symptomless, even when they are very large (one of our cases was found by chance in a radiological examination of the chest), so the differentiation may be arbitrary. Only one of those patients classified as having an acquired lesion has had symptoms for several years.

The most conspicuous fact in Table II is the difference in the incidence of pain and vomiting in the congenital and the acquired forms of the sliding hernia. This may be in part because small children cannot describe their symptoms, but the nurses in the paediatric department, where most of our children have been warded, have especially been asked to look for signs of pain and distress. Actually the only patients complaining of pain in this group were twin girls, 15 years old, who both had peptic ulcers in the oesophagus.

A symptom which, according to the literature, is common is bleeding, either from an established peptic ulcer or from oesophagitis. It is to the credit of Allison (1948) to have called attention to the fact that the sliding hernias very often are complicated by oesophagitis and peptic ulcer, which when healing may lead to stricture. Through the herniation of the cardia the normal pinchcock function of the hiatus, as well as the valve function of the cardia, are compromised, thus allowing the acid from the stomach to flow freely into the oesophagus. The mucous membrane of the oesophagus is not able to resist peptic digestion and hence regurgitation leads to ulceration and inflammation. In our grown-up patients only one gave a history of haematemesis and melaena leading to anaemia, and here the radiological examination revealed a small sliding hernia, but no signs of peptic ulcer or oesophagitis. Peptic ulcer or stricture was demonstrated in three other patients belonging to the acquired sliding hernias, but in none of them was bleeding found. The stools have not been systematically examined for blood, and some of the case records are lacking on that point. It is only in the congenital sliding hernias that bleeding has been a common symptom; we found it to occur in 15 of the 19 patients. A peptic ulcer was demonstrated in six of these children, all belonging to the oldest of this group. 


\section{Operative Technique}

The surgical treatment has, with some exceptions, been the same in all our cases. We have approached the hernia through a left-sided thoracotomy with resection of the eignth or ninth rib. The hernia together with a varying part of the lower oesophagus has been freed from adhesions to the surrounding structures, the hernial sac has been extirpated, and we have taken special care in preparing the diaphragmatic crura until the red muscle fibres became visible ; the diaphragm itself has only been opened on a few occasions. Then the stomach and the cardia have been reduced beneath the diaphragm and the hiatus has been closed around the oesophagus with two or three silk sutures behind, and one in front of, the gullet ; those two nearest to the oesophagus, including its wall. In this way we have tried to narrow the hiatus so that a finger could just be passed beside the oesophagus. In some cases the phrenic nerve has been crushed. Unfortunately this has not always been mentioned in our records. Fifty-four cases have been operated upon according to this technique. One patient developed a perforation of the incarcerated stomach whilst in hospital. He was operated upon immediately and survived. He was a 15-year-old boy with a very large para-oesophageal hernia situated in the right pleural cavity. The technique used did not differ from our usual one, with the exception of the closure of the perforation.

\section{Other Operative Procedures}

Three cases have been operated on by the abdominal route, using the technique advocated by Harrington (1948). Two of these were the first treated in the department, and they were both grown-up women with small sliding hernias. In both the abdominal operation was preceded by exairesis of the left phrenic nerve. The third was a child with a large para-oesophageal hernia located in the right pleural cavity. In a similar case the operation was also performed by the abdominal route, but, as the hernia recurred in the first days after the operation, the patient was reoperated upon by the transthoracic route four weeks later.

Three cases were operated upon transthoracically, but using a different technique. In one, suffering from a congenital sliding hernia with peptic ulcer in the oesophagus, a gastro-oesophageal resection had to be performed. The ulcer was penetrating the wall of the oesophagus and was firmly adherent to the aorta. The patient has now been observed for nearly three years, and his oesophago-gastrostomy is functioning well ; he has no signs of oesophagitis. In another case of congenital sliding hernia, without ulcer, no attempt was made to reduce the hernia. At the time this child was operated upon we had not fully comprehended the pathogenesis of the condition. It was thought that the bleeding was caused by incarceration of the stomach in the hiatus. Therefore, the hiatus was enlarged and again fixed to the stomach. The patient did not get relief from this operation and she has recently been reoperated upon. In the third case, a man who had an acquired sliding hernia and possibly a peptic ulcer as well, a thoracotomy was performed with freeing adhesions around the cardia and the lower part of the oesophagus. An attempt to reduce the hernia was not made. He has been well since that time.

\section{Casualties}

We have lost two of our patients following the operation, both in the older age group. One patient, a 55-year-old woman, with a small sliding hernia, got a pulmonary embolus on the fourth post-operative day leading to instantaneous death. The other, a 58-year-old woman, had a large para-oesophageal hernia. During the operation the right pleura was accidentally opened. The accident was recognized at the end of the operation, the pleural cavities were both drained, but she developed 
a total atelectasis of the right lung. Though she was aspirated bronchoscopically, the lung did not expand, and she died four days after the operation. Besides these two we have not had serious complications in the post-operative course. A complication, especially in the children, has been acute stomach dilatation, probably caused by trauma of the vagus nerves during the operation.

\section{RE-EXAMINATION}

All the patients operated on before January 1, 1950, have been called up for a re-examination, including a radiological study of the oesophagus and the stomach. We have not contacted personally only two patients, both from the provinces ; but they have both had a radiological examination at their regional hospital, and the pictures have been sent to us for evaluation. Besides the two patients, who died as a result of the operation, one has died a year after the operation from a cancer of the breast with liver metastases. We have no information about her condition while she was alive, but according to the necropsy there was no recurrence of the diaphragmatic hernia. In addition, all the children operated on in 1950 have been called up for re-examination, and, except the twin girls, they have all presented themselves. The time elapsing after the operation has in all the cases been more than six months. Sixteen grown-ups operated on during 1950 have not been systematically re-examined. One of them had a recurrence one month after the operation, but he has not been seen since that; another has had a reoperation nine months after the operation because of a recurrence. Four other patients have presented themselves three to four months after the operation and have on that occasion been examined radiologically. In this way we have got information on 45 patients, of whom 42 have had herniotomies. In the three remaining cases the hernia was not reduced.

We have found that a radiological examination is especially important. The symptomatology of hiatus hernia is so complex and unspecific that it is impossible to assess if the operation has been a success or not simply on the patient's statements. Radiological examination is the only reliable method.

The criteria for the reduction of the hernia is that a protrusion of the stomach can no longer be demonstrated radiologically, i.e., that the gastric mucosal pattern is no longer seen above the diaphragm. Even the slightest protrusion of the stomach through the hiatus has been regarded as a recurrence.

When the patients are screened shortly after the operation a narrowing of the oesophagus caused by oedema in the hiatus region may be demonstrated in many cases; this narrowing soon disappears. When looking for a recurrence it is important that the examination be performed in the supine position, preferably in a slight Trendelenburg position. Under these conditions the lower part of the oesophagus and the cardia are best demonstrated. When there is a large recurrence the hernia will be seen in this position and easily diagnosed. When it is a small recurrence, it is necessary to study the mucosal pattern of the oesophagus. On pictures taken during deep inspiration it may be possible to demonstrate how the smooth mucosal pattern of the oesophagus changes to coarse gastric folds two to several centimetres above the diaphragm. In some cases it has been possible to show that the hiatus is wider than normal. 
TABLE III

RESUlTS OF THIRTY-SIX HeRNIOTOMIES

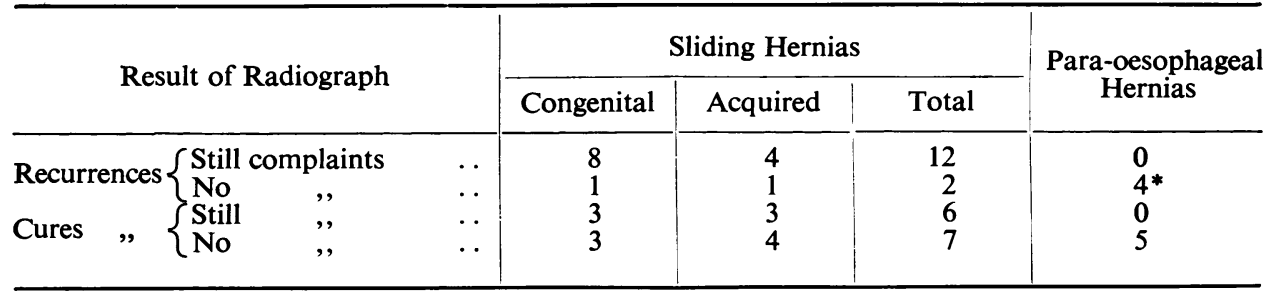

* All sliding hernias.

Table III, including all the patients who have had a herniotomy at least six months before the re-examination, shows the result of our re-examination.

In Table IV is shown the result in the six patients operated upon in 1950 who have been re-examined; they were all cases of sliding hernia.

TABLE IV

RESUltS OF Six HeRNIOTOMIES

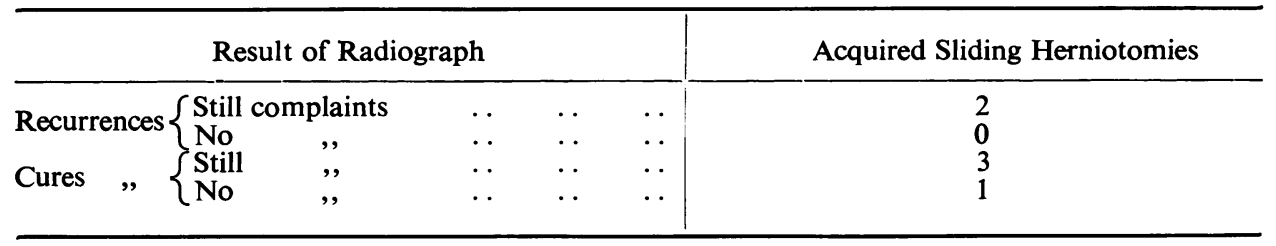

The results in the para-oesophageal type are satisfactory. The patients have all been relieved of their pain, though four of them according to the radiological examination show recurrences. These recurrences were small and belonged to the sliding type.

In the sliding hernias, on the other hand, the results are discouraging; not more than $25 \%$ can be called completely cured and not less than $50 \%$ show a recurrence on the $x$-ray examination, and only two of these have no complaints. There seems to be no significant difference between the results in the congenital hernias and those in the acquired sliding hernias. The poor results in the sliding congenital hernias have been especially disappointing to us. In a previous paper (Husfeldt, Thomsen, and Wamberg, 1951) our first eight cases were followed up and the results then seemed to be promising, but the time elapsing after the operation was short.

Six of the relapses have now been reoperated upon; four belonging to the congenital group, two to the acquired group. The reoperation in four of them has been performed so recently that the result cannot yet be evaluated. In two the second operation was performed over a year ago. Both patients are radiologically cured. One, a 3-year-old boy, has no symptoms, but the other, a 46-yearold woman, is still complaining as much as before.

More than half of the patients with sliding hernias, though radiologically cured, are still complaining of the same symptoms as before the operation. In the congenital group there are two who still have regurgitations; in one of them it can 
also be demonstrated by radiological examination. The third patient had a peptic ulcer and stricture of the oesophagus; she still has the stricture and needs periodically treatment with bougies, but the hernia has been reduced. The five patients in the acquired group all complain of distinct dyspepsia, which has persisted practically unchanged after the operation. In our opinion, it is most likely that their complaints have been faultily attributed to their hernia. The sixth patient maintains that she can only swallow when she stretches both arms high up. According to the psychiatrist, who has seen the patient after the operation, she has a mononeurosis.

Nine patients had peptic ulcers and strictures of the oesophagus. Of these only four, who have had a herniotomy, have been re-examined. Three have a recurrence of the hernia, and they all have complaints referable to their stricture. The twin girls with peptic ulcer have been seen one month after the operation, and on that occasion they both had small recurrences, and their complaints were practically the same.

In four cases the operation has been performed by the abdominal route; one patient had a recurrence immediately afterwards and was reoperated transthoracically four weeks later. The others have no recurrences, and they have been relieved of their complaints. These few cases do not argue in favour of the abdominal operation, and it should also be mentioned that one of our cases operated upon transthoracically was operated upon for a recurrence after an abdominal herniotomy for hiatus hernia. She is cured after her last operation.

In the literature only Soutter's (1947) material is comparable to ours, but the number of cases followed up is small. He has analysed the cases of hiatus hernia treated surgically at the Massachusetts General Hospital from 1920 to 1947. From 1920 to 1940,25 had been operated upon by the abdominal route. Immediate studies before the patients left the hospital showed eight recurrences and five cures; 12 were not studied. A year later two more recurrences were found, but the rest of the material has not been re-examined. From 1940 to 1947,37 hiatus hernias were operated upon by the transthoracic approach. Immediate studies showed two recurrences and 25 cures ; 10 were not examined before leaving the hospital. A year later three more recurrences were found, and six were found to be cured. Twenty-six have not been re-examined, i.e., the proved recurrences were five, and the proved cures six.

Harrington in 1948 reported 308 hiatus hernias, all operated on by the abdominal route. He had nine recurrences, five of them without symptoms. Sweet in 1948 reported the late results in 43 patients operated for hiatus hernia by the transthoracic approach, re-examined after more than six months. Thirty-nine had complete symptomatic relief, three partial relief, and only one was not relieved. In these statistics no difference is made between the type of the hernias, if they were sliding or para-oesophageal, congenital or acquired. Harrington and Sweet do not mention if their patients have been re-examined radiologically, and this makes comparison with our material impossible.

\section{Discussion}

When looking for an explanation for our many failures and radiological recurrences, we will first have to scrutinize our indications for operation and next our operative technique. 
It may be that our indications have been too wide in the acquired sliding hernias. It is well known that this condition is a common finding in older people, especially in women above 40 to 50 years, and operation is only indicated when the symptoms are severe and the patient has been thoroughly examined for any pre-existing or coexisting lesion of which the symptoms might falsely be attributed to the hernia. All the same, in this group there may be possibilities of mistakes, because the symptoms are so unspecific. On the other hand, we do not think we have been too active in our indication for surgery in the uncomplicated congenital hernias and the para-oesophageal hernias.

The cases complicated by peptic ulcer and stricture seem to represent a special question. Herniotomy alone, if at all feasible, will perhaps cure peptic ulceration, but the stricture is not influenced. The number re-examined is small (four cases), but the results are discouraging and it is doubtful if we have done good by operating. We have had a satisfactory result in one case treated with gastro-oesophageal resection. The best treatment is no doubt prophylactic; sliding hernias, especially of the congenital type, should be operated as early as possible before peptic ulcer and stricture supervene.

Though our technique does not differ from that usually described in the literature, we feel that it has not been satisfactory, and if we are going to operate upon hiatus hernias on a large scale it will have to be changed. We are convinced that the transthoracic route is the best, but in our experience one cannot rely on the fixation of the oesophagus to the hiatus, because the muscular wall of the oesophagus is so frail and easily tears.

In our last six cases, not included in this material, we have used a new technique, the principles of which have been: a better fixation of the cardia below the diaphragm and a reconstruction of the valve of the cardia. To obtain this we have opened the diaphragm by a parahiatal incision so that, after reduction of the hernia, we can fix the fundus of the stomach to the abdominal surface of the diaphragm and suture the stomach to the subdiaphragmatic part of the oesophagus over an area of 2-3 cm., thus reconstructing the acute angle between these two organs. This should help to prevent further regurgitation. The hiatus has been narrowed in the

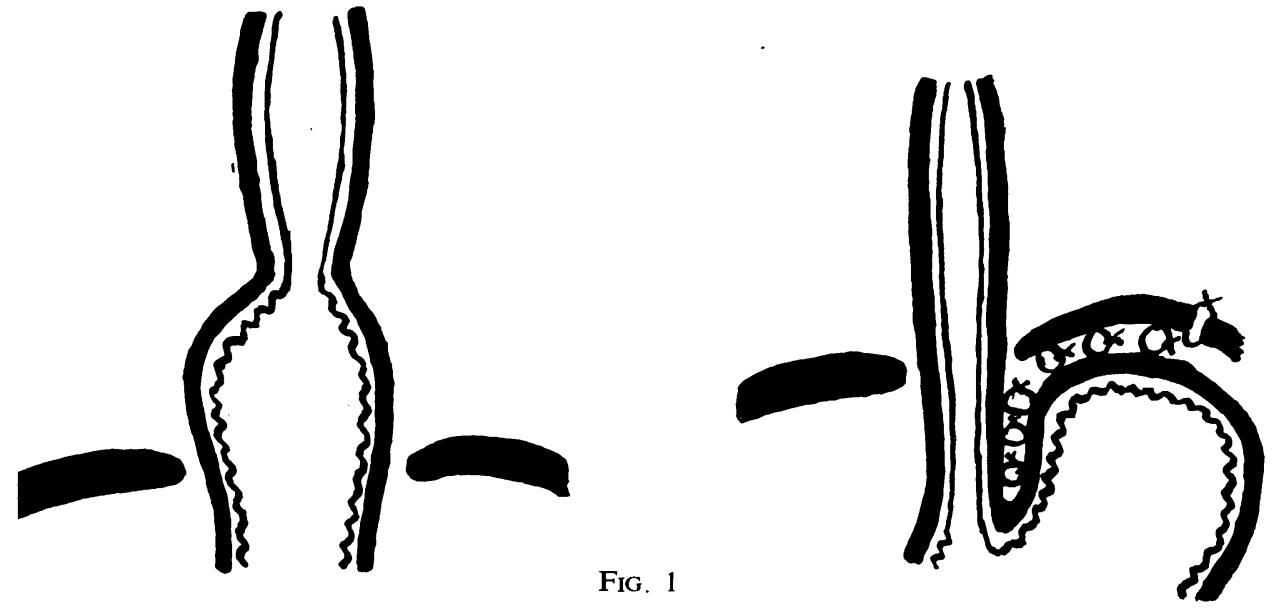

FIG. 1 
usual way, but we have not found it necessary to fix the oesophagus to the hiatus (Fig. 1). The primary results have been satisfactory both clinically and radiologically, but it is too early to evaluate the late results.

The para-oesophageal hernias should not be treated in this way. The sliding hernias, which we have seen occur after operations for para-oesophageal hernias, have taught us that it is wrong to interfere with the normal fixation of the oesophagus and the cardia. The correct treatment is simply to reduce the hernia, extirpate the hernial sac, and narrow the wide hiatus. In some cases with rather big hernias it may be necessary to open the diaphragm by a parahiatal incision and pull the stomach down while closing the hiatus.

\section{SUMMARY}

Sixty cases of hiatus hernia operated on during the years 1943 to 1950 in the department of thoracic surgery of the University Hospital of Copenhagen have been reviewed, and 45 have been followed up and re-examined radiologically. The time elapsing from the operation to the re-examination in most cases has been about a year or more ; in a few cases only it has not been more than three to four months.

Only $25 \%$ have been both clinically and radiologically cured. Nearly $50 \%$ show a recurrence by $x$-ray examination, but a fourth of these are clinically cured. Twenty-five per cent. have not been relieved of their complaints, though they have no recurrence of their hernia radiologically.

From these results we conclude that the technique usually described is not satisfactory, and we indicate a modification aiming at a better fixation of the cardia and a reconstruction of the valve of the cardia. This method is now used in the department, and the primary results have been promising.

We wish to express our most grateful thanks to Professor E. Husfeldt, in whose department all the operations were performed, and who has looked through and criticized this paper, and to Professor P. Flemming Möller for the opportunity to perform all the follow-up $x$-ray examinations.

\section{REFERENCES}

Åkerlund, А. (1926). . Acta radiol., Stockh., 6, 3.

Allison, P. R. (1948). Thorax, 3, 20.

Harrington, St. W. (1948). Surg. Gynec. Obstet., 86, 735.

Husfeldt, E., Thomsen, G., and Wamberg, E. (1951). Thorax, 6, 56.

Nuboer, J. F. (1949). 'Ned. Tijdschr. Geneesk., 93, 3384.

Soutter, L. (1947). Surg. Clin. N. Amer., 27, 1121.

Sweet, R. H. (1948). New Engl. J. Med., 238, 649. 